\title{
Questões não só alemãs
}

Norbert ELIAS. Os alemães. A luta pelo poder e a evolução do habitus nos séculos XIX e XX. Organização de M. Schroeter. Tradução de A. Cabral. Revisão técnica de A. Daher. Rio de Janeiro, Zahar, 1997. 431 páginas.

\section{Leopoldo Waizbort}

Os Estudos sobre os alemães. Lutas de poder e desenvolvimento do habitusnos séculos XIX e XX, publicados em 1989, estão em continuidade direta com o livro que Norbert Elias (1897-1990) publicara 50 anos antes, Sobre o processo de civilização. Investigações psicogenéticas e sociogenéticas. Embora o livro mais antigo tenha sido dedicado, sobretudo, a uma investigação sobre a "França", já desde o primeiro capítulo seus leitores tiveram a atenção deslocada para o caráter comparativo do estudo, na investigação sociogenética da contraposição entre "cultura" e" civilização" na Alemanha e na França. Mais adiante, em meio à investigação do processo de longa duração da formação do Estado francês, Elias dedicou um "Excurso sobre algumas distinções no curso de desenvolvimento da Inglaterra, França e Alemanha". Os Estudos sobre os alemães vêm dar continuidade às investigações comparativo-distintivas de Elias, que objetivam pensar os nexos entre o processo de formação do Estado, por um lado, e o desenvolvimento do habitus, por outro (nos termos do livro de 1939: sociogênese e psicogênese, transformações na estrutura da sociedade e transformações na estrutura da personalidade).
Os Estudos são, em certa medida, "respostas" de Elias a quatro grandes críticas e, conseqüentemente, problemas que lhe foram dirigidas ao longo da recepção truncada e tardia de sua obra (o que significa que esta é uma das possibilidades de leitura do livro). Em primeiro lugar, uma crítica lhe acusou de tratar o processo de formação do Estado (e da psicogênese a ele correlata) baseado apenas no estudo do caso francês, deixando com isso de lado variantes outras, mas não menos significativas, do processo de formação do Estado moderno. Diante dessas críticas, Elias tratou de apresentar, nos Estudos, outras vertentes do processo de formação do Estado: uma análise rápida do "modelo" holandês, na" Introdução", e as análises mais detidas do "modelo" alemão, que dão corpo e título ao volume (também são feitas, de passagem, menções ao" modelo" inglês).

Em segundo lugar, os Estudos se pretendem uma resposta às críticas de evolucionismo social que desde cedo foram dirigidas ao autor. Emblemática, neste aspecto, é a afirmação com a qual Elias abre seu estudo "Civilização e 
violência":" A civilização da qual falo nunca terminou e está sempre em perigo" (p. 161; ver também p. 280).

Em terceiro lugar, trata-se de enfrentar o problema da "informalização" dos comportamentos no interior do modelo explicativo do processo de civilização. O" afrouxamento" nos padrões de comportamento ao longo do século XX é relacionado com as transformações na estrutura da sociedade, em especial com as transformações do Estado e com as transformações nos equilíbrios de poder entre os grupos (tema clássico em Elias), sobretudo a diminuição nos diferenciais de poder. Aqui Elias varia a sua tese básica de Sobre o processo de civilização, ao afirmar que deslocamentos de poder andam de mãos dadas com transformações da consciência (pp. 37-38). As investigações acerca do "arco de informalidadeformalidade de uma sociedade" (p. 39) propiciam uma chance excelente para Elias desdobrar sua maestria na conjugação de sincronia e diacronia na análise dos fenômenos sociais.

Por fim, em quarto lugar, o autor enfrenta o desafio de explicar a barbárie do nacional-socialismo no interior do modelo do processo de civilização, o que leva a um desenvolvimento da teoria, dando sobretudo atenção a contraprocessos que se desenvolvem no interior do processo e formulando a idéia do processo (e dos surtos) de descivilização. Como se vê, esse leque de questões ultrapassa, e em muito, questões" alemãs"; a Alemanha é antes utilizada como objeto privilegiado para pensar problemas que são muito mais amplos.

$\mathrm{O}$ argumento narrativo central dos Estudos um argumento tão simples quanto brilhante é uma retomada, em registro ampliado, do que Elias havia proposto em seu livro de 1939. Elias descrevera a nobreza guerreira, indicando o seu longo processo de "acortesamento" (Verhoeflichung) na França, isto é, a transformação de uma nobreza guerreira em uma nobreza cortesã um processo inextricavelmente ligado ao processo de centralização e integração nacional, ou seja, atrelado ao processo de formação do Estado nacional. Ligado a isto, a simbiose entre nobreza assentada na corte e burguesia, simbiose esta que permitiu, sobretudo ao longo dos séculos XVII e XVIII, uma comunicação cada vez mais forte entre estes dois estratos sociais na França. Em contraste com o "caso" (ou "modelo") francês, a Alemanha não apresentou, em seu desenvolvimento histórico, a formação de um Estado nacional nos mesmos moldes (e tudo o que isto implica); a formação tardia do Estado alemão trará implicações específicas. Como o Estado não se unifica, e isto significa a inexistência de uma corte centralizadora (como Paris e Versalhes), não há o processo de assentamento da nobreza na corte; com isso não se realiza aquela metamorfose de nobreza guerreira em nobreza cortesã. Um dos resultados desse processo é que, quando o Estado se unifica no II Reich, ele se unifica sob a liderança de uma nobreza que não se assentou na corte e permanece ligada ao seu ethos guerreiro original não por acaso, o locus por excelência da nobreza prussiana, isto é, do estrato social que realiza a unificação alemã, é o exército. Além disso, não ocorre na Alemanha aquela simbiose comunicativa entre nobreza e burguesia, muito pelo contrário um tema que Elias já havia discutido de modo muito sugestivo no primeiro capítulo de Sobre o processo e que é retomado no capítulo 2 dos Estudos. Nobreza e burguesia permanecem em isolamento entre si. Um exemplo forte deste isolamento é o fato de a burguesia falar (e escrever) alemão e o rei e a nobreza falarem francês. Esta fratura é uma das marcas do processo alemão, das continuidades e descontinuidades alemãs. A burguesia que fala alemão é a burguesia dos valores humanitários e universais. Sua tentativa de revolução e unificação nacional, nos idos de 1848, fracassou, e o resultado foi uma unificação nacional tardia, feita sob os auspícios da nobreza (e conseqüentemente do exército), nas guerras de 1870-71. É uma unificação peculiar, porque se faz de fora para dentro, no confronto com o inimigo francês.

A unificação sob o signo da nobreza significou, nos termos de Elias, a capitulação da burguesia diante da nobreza. "A vitória dos exércitos alemães sobre a França foi ao mesmo tempo uma vitória da nobreza alemã sobre a burguesia alemã." (p. 26). Conseqüência disso é que a Alemanha unificada toma para si o ethos guerreiro, característico da nobreza, como ethos nacional. O modelo de 
comportamento baseado na ordem e no mando, na disciplina do exército, no código de honra, é assimilado por amplos círculos burgueses. A burguesia adota um padrão de comportamento, sensibilidade, consciência, habitus que é gerado na nobreza. Ele se difunde do seu estrato social originário para os outros estratos sociais, sobretudo, inicialmente, para a burguesia e os estratos médios. Assim, o ethos guerreiro, característico de um estrato social específico, que experimentou um desenvolvimento peculiar por não ter se assentado na corte , torna-se o modelo de um habitus nacional. Isto significou, para os alemães, a aceitação do "emprego ilimitado do poder e violência" (p. 27; ver também p. 167) como instrumentos legítimos da política e da vida social na nação, como meios privilegiados na resolução de conflitos internos e externos.

A tensão entre violência e pacificação é um dos núcleos do volume, como já o fora no de 1939. As continuidades e descontinuidades alemãs permitem explorar em detalhe os nexos que articulam, historicamente, a pacificação enquanto resultado do processo de formação do Estado e a irrupção da violência em seu interior, o que implica, claro está, romper com aquela crítica que se fazia à teoria do processo de civilização, de que ela seria uma teleologia histórica. Com isso, as acusações de etnocentrismo também caem por água abaixo. Se o processo de civilização está sempre em perigo, isto significa que a pacificação é algo construído a cada instante, uma tarefa e um desafio permanentes (veja-se, por exemplo, o que diz Enzensberger em Visões da guerra civi). Se o habitusgrupal (por exemplo, nacional) incorporou, sob a forma de autocoações, o controle da violência no trato dos conflitos, esta tarefa parece facilitada, mas de modo algum está resolvida. Ela não se resolve jamais. Isto porque, para Elias, sendo os seres humanos naturalmente diferentes entre si, eles necessariamente se relacionam uns com os outros de modo conflituoso. O conflito é inerente às relações sociais, isto é, humanas. O processo de civilização é justamente a regulação dos conflitos mediante coações exteriores e autocoações; quando elas não são "eficazes", o conflito eclode sob a forma de violência. "Não é a agressividade que deflagra os conflitos, são os conflitos que deflagram a agressividade." (p. 402).

A penetração do ethos guerreiro na burguesia do II Reich é exemplificada no estudo da sociedade que dá e exige satisfações, isto é, da prática dos duelos, esse" cultivo socialmente regulado da violência" (p. 30) que indica, de maneira sugestiva, a incorporação dos modelos de conduta da nobreza pela burguesia e, ao mesmo tempo, as idiossincrasias do Estado nacional, incapaz de conter o uso ritual generalizado da violência. Isto implica, ainda, a aceitação do fato de que os homens são diferenciados nobres ou não, honrados ou não, arianos ou não , de que há uma hierarquia social acentuada que deve ser preservada. E por conta disto Elias destaca a idéia de que há "modelos sancionados socialmente de violência e de desigualdade" (p. 30). A essa altura, já não se sabe muito bem se ele está falando do Brasil ou da Alemanha.

O ethos guerreiro, aclimatado em habitus nacional alemão, dá lugar a uma explicação poderosa dos desenvolvimentos ocorridos por aquelas bandas: explica a dificuldade de implantação e implementação de um regime democrático. Democracia exige diálogo, um diálogo cujo modelo inicial teria sido a comunicação entre nobreza e burguesia (como na França) ou entre o rei e a aristocracia (como na Inglaterra). A oposição entre ditadura e democracia está, portanto, delineada. Elias discute a naturalidade com que os alemães aceitam a presença de milícias paramilitares e a" inadequação" de procedimentos democráticos na resolução de suas dificuldades. Tendo se unificado através da guerra, nada mais natural do que o uso da violência. Esta é a chave para se pensar o período que vai de 1870 a 1945. Elias menciona a opinião corrente na época da República de Weimar, segundo a qual os" membros do Parlamento [...] tagarelavam muito, mas faziam muito pouco" (p. 177). Este é o argumento do pensamento conservador do século XIX. Donoso Cortés estigmatizava a burguesia como "clasa discutidora"; quem o retoma é Carl Schmitt, cujo conceito do político se condensa na polarização amigo/inimigo. Ora, tal polarização pode ser lida, com enorme proveito, como resultado do processo apontado por Elias, como uma manifestação do ethos guerreiro característico 
do babitus nacional alemão. $\mathrm{O}$ parlamento, por sua vez (que Elias discutiu, tendo em vista a Inglaterra, em $A$ busca da excitação), em oposição ao modelo da ordem e do mando, implica diálogo, convencimento, persuasão, consenso, acordo. Os alemães, entretanto, permanecem refratários a uma solução dos conflitos sem a utilização da violência; a crítica e a incapacidade de aceitar e implementar um regime parlamentar como mostra Elias reiteradamente na análise do período da República de Weimarapontam para a solução dos conflitos por vias violentas, e a "guerra total" de Hitler (assim como a "solução final") nada mais é do que a potencialização dessa lógica (dirigida, respectivamente, aos "inimigos" externos e internos).

A experiência da nação tardia é fomentadora de um sentimento de insegurança que marca o habitus nacional. $\mathrm{O}$ sonho do passado glorioso, modelado pelo ideal do I Reich, permite compreender Hitler como um ponto de condensação em um processo de longo prazo caracterizado por um sentimento de inferioridade perante as outras nações que precisa ser superado. A "crença nacional" como motivo de mobilização das massas para a garantia da "nação" diante de perigos reais ou imaginários dá lugar à religião nacional-socialista: a unyo mistica, como teria dito Weber, com o líder.

Um outro fenômeno estudado por Elias na mesma chave de interpretação, o terrorismo na Alemanha, é um instigante modelo para se pensar os usos da violência entre nós em casos tão díspares como a guerrilha e a violência e criminalidade nas grandes cidades. A explicação de Elias, baseada em uma poderosa sociologia das gerações e em uma retomada do diagnóstico weberiano da perda de sentido, sugere sua verificação em fenômenos diferentes mas suscetíveis de aproximação.

A incompletude das explicações de curta duração fica evidente por meio de uma argumentação em negativo. A partir do exemplo da República de Weimar, Elias chama a atenção para o fato de que um regime formal e legalmente "democrático" não significa absolutamente que haja democracia. Se há sentido em articular as transformações na estrutura da sociedade com as transformações na estrutura da personalidade, isto significa que apenas no curso de algumas gerações (segundo Elias, entre três e cinco) é possível falar em "correspondência" entre umas e outras. Ou seja: são necessários muitos anos para que uma democracia "formal" se torne uma democracia de fato, pois isto implica uma estrutura da personalidade correspondente: "Foi uma das mais fantásticas expressões do racionalismo a-histórico dos nossos dias que as pessoas supusessem então (como muitas ainda supõem hoje) que uma democratização de atitudes, crenças e convicções viria na esteira do estabelecimento de instituições democráticoparlamentares" (p. 300; ver também p. 374). Como se vê, Elias não está falando apenas da Alemanha. A transição para um regime democrático é um processo de aprendizado longo e complexo (p. 303), sujeito, a cada instante, a contraprocessos.

As reflexões de Elias sobre a Alemanha estão, curiosamente, próximas das de Adorno, sobretudo ao compartilharem a idéia de uma "Verarbeitung der Vergangenheit" (p. 31; ver também pp. 370 e ss.), uma expressão de Adorno difícil de traduzir que aparece em Elias e que significa trabalhar e retrabalhar o passado, acertar as contas com o passado e não permitir o esquecimento do que ocorreu. Elias afirma que a tarefa da Sociologia, com caçadora de mitos, é trazer à consciência o que estava esquecido (p. 30). Adorno escreveu um texto famoso com esse título e Habermas, em um livro relativamente recente (Die Normalitaet einer Berliner Republik, 1995), retomou a questão adorniana (e eliasiana) pensando nas suas exigências hoje. O livro de Habermas é um surpreendente complemento político e contemporâneo, da maior envergadura, para ser lido em paralelo com os Estudos.

Como sabem seus leitores, a sociologia eliasiana é uma sociologia dos grupos. Nos Estudos, a visada do autor privilegia a formação de um tipo específico de identidade coletiva, a nacional; mas suas reflexões pretendem de fato generalidade e são modelos para pensar os processos de formação de identidades coletivas em geral, o que transparece, por exemplo, nos conceitos de "imagemnós"," ideal-nós". Se aqui enfatizei o viés 
macrossociológico do livro, cabe destacar que ele é contrabalançado pelas ricas etnografias com que Elias vai guarnecendo suas reflexões; o entrelaçamento dos níveis micro e macro, como se sabe, é uma das realizações mais bem-sucedidas de Elias.

Como o livro é muito rico e abre muitas possibilidades de leitura, seria impossível inventariá-lo por completo. Isto posto, gostaria de arriscar uma hipótese para uma possível incorporação das reflexões de Elias por aqui. Apesar da relativa facilidade com que seus modelos se deixam aclimatar, penso que muitas vezes perde-se de vista o nexo que é o núcleo do projeto eliasiano, isto é, o entrelaçamento de psicogênese e sociogênese, pensado no interior de um processo de longa ou longuíssima duração. Por exemplo: só tem sentido incorporar as reflexões acerca da pacificação das sociedades no âmbito do processo de longa duração de formação do Estado. A questão é, portanto, como pensar o processo de longa duração do Estado brasileiro. Encaminhamento muito sugestivo (embora sem pensar em Elias) é o proposto por Richard Morse em O espelho de Próspero, uma tentativa de pensar contrastivamente as "escolhas" que ganham corpo na ibero-américa e na anglo-américa. Temos aí expressas duas vertentes diferentes do processo de formação do Estado na Europa que são" transplantadas" para além-mar. Os ruídos de tal transplante, por um lado, e o significado desse transplante no registro da psicogênese, por outro, são um tema sensacional a ser explorado a partir de Elias. Isto significa, por exemplo, desdobrar a fundo "iberismo" e "americanismo" e as diferenças da colonização espanhola ante a portuguesa, remetendo a processos específicos de longuíssima duração que reverberam em profundidade na economia psíquica dos indivíduos ou, se preferirem, no" caráter nacional", no babitus nacional. Penso, para dar apenas um exemplo, em como é possível ler as "interpretações" de longa duração de Sérgio Buarque de Holanda, ou Raymundo Faoro etc., sob o foco de luz da lanterna de Elias (ver, por exemplo, p. 16).

Seja-me permitido, para terminar, algumas linhas sobre a tradução brasileira. Ela repete o erro fatal de ser uma tradução de segunda mão: ao invés de traduzir o original em língua alemã, a editora optou por traduzir a tradução inglesa. Os ruídos que se infiltram inevitavelmente em toda tradução reproduzem-se, no caso das traduções das traduções, de modo diabólico. O que poderia ser uma boa solução na versão inglesa muitas vezes leva a uma má solução na versão brasileira. Seus tropeços já se mostram desde o título e, como um ostinato, acompanham o curso do volume. Veja-se o título do livro:

a) Ao invés de "lutas de poder", verteu-se "a luta pelo poder", singularizando o que é essencialmente uma pluralidade e dando margem à idéia de que o poder é algo que se tem, como se fosse um amuleto (algo que o próprio Elias se esforçou, numerosas vezes, em criticar). A idéia do todo relacional em Elias, de resto representada no volume, sintoniza-se com a idéia das lutas de poder, que remetem ao conjunto das relações sociais, que são sempre relações de poder, e não propriamente com a idéia da luta pelo poder, que acena para o sentido mais macropolítico da questão e despreza as articulações microssociais, tão relevantes, para Elias, quanto as macro.

b) Ao invés de "desenvolvimento do habitus", verteu-se" evolução do habitus", um pecado mortal contra Elias, já que um dos objetivos do livro é responder às críticas de evolucionismo que lhe foram feitas. Elias preocupou-se em distinguir os conceitos de "evolução" e" desenvolvimento": o primeiro está restrito ao âmbito da natureza e das ciências que a tem como objeto; as ciências humanas não podem falar jamais em "evolução", mas apenas em "desenvolvimento". A tradução joga contra Elias e a favor de seus críticos.

c) Ao invés de "estudos sobre os alemães", verteu-se "os alemães", sugerindo um escopo totalizador e essencialista que é completamente estranho ao autor. Ao falar em "estudos", Elias por um lado tem em vista o caráter fragmentário do livro, que reúne textos escritos em épocas diferentes e com graus muito diversos de desenvolvimento. Por outro lado, e ainda mais importante, é preciso ter em vista que os "estudos" significam que se trata de uma abordagem fragmentária, inacabada e inacabável, pois que se investiga um processo que está em curso e que, por essa simples razão, não permite uma abordagem que diga "o que 
é", mas apenas que se aproxime, de ângulos variados, de um fenômeno cuja própria circunscrição é difícil e nunca acabada.

d) Por fim, alguns exemplos de erros que, mesmo sem ter feito um cotejo sistemático com o original, saltam aos olhos ao longo do volume: "dimensão formalidade-informalidade de uma sociedade", ao invés de "arco de informalidadeformalidade de uma sociedade" (p. 39); "ordenação dos Estados", ao invés de "ordem segundo estratos/estamentos" (p. 126); a seguinte pérola: "mundanos íntimos", ao invés de "intramundanos", que é terminologia explicitamente weberiana (p. 143); "monopólio da força", ao invés de "monopólio da violência" (p. 162); "1870-77", ao invés de "1870-71" (p. 168); "guerra de atrito", ao invés de "guerra de posições", referida à guerra de trincheiras (p. 169); "violento processo de duplo vínculo", ao invés de "processo de violência de duplo vínculo", pois se trata do importante conceito de
"double-bind/Doppelbinder" (p. 173); "compromissos", ao invés de "acordos" (p. 183); "oficial", ao invés de "líder", para traduzir "Fuehrer", já que Elias joga com o significado do termo (p. 194); "necessidade de significação", ao invés de "necessidade de sentido", pois se trata de referência à idéia weberiana da perda de sentido (p. 209); "funções de compulsão", ao invés de "funções de coação" (p. 303); "identificação com o opressor", ao invés de "internalização do opressor" (p. 303), e assim por diante. Elias sai cambaleando da tradução nacional; em compensação, um dos pontos fortes da edição brasileira é a capa, que retrata a Quadriga de Johann Gottfried Schadow, posta sob a Porta de Brandenburgo, no centro de Berlim, no coração da Prússia, do II Reich, do III Reich e da Alemanha reunificada. A Quadriga, símbolo prussiano que se tornou monumento nacional, marca, como testemunha, as idiossincrasias do "destino de um povo", da "pobre e autodestrutiva Alemanha" (pp. 30 e 382). A questão que me intriga é: qual haveria de ser nosso símbolo e monumento?

\section{LEOPOLDO WAIZBORT}

é professor do Departamento de Sociologia da Universidade de São Paulo (USP). 